\title{
SIMULAÇÃO E ANÁLISE TÉCNICA ECONÔMICA DA OBTENÇÃO DE BIOETANOL A PARTIR DAS FRAÇÕES SACARÍNEA E LIGNOCELULÓSICA DO SORGO SACARINO
}

\author{
G. A. L. SOUZA ${ }^{1}$, G. C. MENEZES ${ }^{1}$ e F. Á. RODRIGUES ${ }^{1}$ \\ ${ }^{1}$ Universidade Federal de Viçosa, Departamento de Química \\ E-mail: farrodrigues1@gmail.com
}

\begin{abstract}
RESUMO: A cana-de-açúcar é a principal matéria-prima para produção de etanol no Brasil, entretanto ela possui restrições quanto ao seu ciclo de produção. Dessa forma, o sorgo sacarino, pode ser visto como uma alternativa durante a entressafra canavieira. Utilizando o software Aspen HYSYS, foi realizada a simulação da produção integrada de etanol de primeira e segunda geração a partir do sorgo sacarino. Para produção do último, o bagaço do sorgo deve ser submetido a um pré-tratamento. Nesse trabalho, foram avaliados os pré-tratamentos hidrotérmico, ácido diluído e explosão a vapor; cujos custos de produção integrada foram estimados, após análise econômica, em US\$1,205, US\$1,244 e US\$1,367, por quilo de etanol, respectivamente. Pela variação paramétrica, observou-se que a produção de etanol é economicamente viável para maiores quantidades de material processado. O menor valor obtido foi US\$0,987/kg etanol, utilizando o pré-tratamento hidrotérmico, processando 650 ton/h de sorgo sacarino.
\end{abstract}

PALAVRAS-CHAVE: Sorgo Sacarino; Bioetanol de Primeira e Segunda Geração; Prétratamento; Simulação; Aspen HYSYS; Análise Econômica.

\section{INTRODUÇÃO}

Há algum tempo as preocupações com os impactos ambientais gerados pelos combustíveis fósseis vêm sendo tema no cenário mundial. Nesse contexto, pesquisas visando a criação de fontes renováveis de energia vêm sendo cada vez mais desenvolvidas.

O sorgo sacarino, [Sorghum bicolor (L.) Moench], é uma cultura rústica originária do Sudão que pode ser cultivada em áreas tropicais, subtropicais e temperadas. O sorgo possui tolerância a estresses abióticos, alta adaptabilidade e pode ser cultivado em diferentes tipos de solo (EMYGDIO, 2010).

O sorgo apresenta um alto teor de açúcares diretamente fermentáveis contidos no colmo, elevada produção de biomassa e seu cultivo pode ser facilmente mecanizado, por ser através de sementes. O sorgo sacarino apresenta um ciclo de 4 meses, enquanto a cana-de- 
açúcar demora um ano. Isto permite que a cultura seja estabelecida e colhida durante a entressafra da cana-de-açúcar, beneficiando a indústria alcooleira, que não ficaria sem matéria-prima para a produção de etanol nesse período (EMYGDIO, 2010).

O etanol de primeira geração, é aquele produzido a partir do caldo, de maneira convencional. A partir do bagaço, que a princípio seria um resíduo da produção, pode-se produzir o etanol de segunda geração (ALBARELLI, 2013).

A matéria lignocelulósica disponível para a produção do etanol de segunda geração, deve passar por um processo de pré tratamento, para que os açucares nela contidos, se tornem disponíveis para fermentação (DIAS, 2008). Alguns autores trazem diferentes pré tratamentos do bagaço do sorgo sacarino, entre eles tem-se eles Sipos (2009) com o pré tratamento de explosão a vapor; Dogaris (2009) e Yu (2008) com o pré tratamento hidrotérmico e Barcelos (2012) com o pré tratamento ácido-alcalino.

O objetivo deste trabalho foi realizar a simulação da produção integrada de etanol de primeira geração (fração sacarínea) e de segunda geração (fração lignocelulósica), utilizando o sorgo sacarino como matéria prima, utilizando os pré-tratamentos hidrotérmico, ácido diluído e explosão a vapor.

Foi realizada uma análise econômica de cada planta integrada, para o cálculo do minimum selling price - MSP, de forma a se avaliar a viabilidade de implantação e comparar com os diferentes processos de produção. Além disso, foi feita uma variação na quantidade de matéria prima processada, para analisar os impactos no custo da produção de acordo com quantidade de etanol produzida.

\section{MATERIAIS E MÉTODOS}

\subsection{Simulação}

Foi utilizado o software Aspen HYSYS 8.8 na simulação de 3 plantas químicas, sendo uma para cada um dos pré-tratamentos do bagaço: o pré tratamento ácido diluído-alcalino, o de explosão a vapor e o hidrotérmico.

\subsubsection{Componentes inseridos no simulador}

Foram inseridos no simulador os componentes de interesse para produção do bioetanol a partir do sorgo sacarino, incluindo os reagentes e catalisadores envolvidos. Esses componentes estão descritos na Tabela 1. Os componentes hipotéticos inseridos no simulador, tiveram seus dados padronizados de acordo com Wooley e Putsche (1996), mostrada na Tabela 2 abaixo. Para o procedimento de simulação, foi utilizada a composição do sorgo sacarino baseado em Barcelos (2012) e May et al.(2012), mostrada na Tabela 2. 
Tabela 1 - Componentes reais e hipotéticos inseridos no simulador.

\begin{tabular}{|c|c|c|}
\hline Componente & Fórmula Química & Nome no Simulador \\
\hline Celulose* & {$\left[\mathrm{C}_{6} \mathrm{H}_{10} \mathrm{O}_{5}\right]_{\mathrm{n}}$} & CELULOSE $^{1}$ \\
\hline Hemicelulose* & {$\left[\mathrm{C}_{5} \mathrm{H}_{8} \mathrm{O}_{4}\right]_{\mathrm{n}}$} & HEMICELULOSE $^{1}$ \\
\hline Lignina* & {$\left[\mathrm{C}_{7,3} \mathrm{H}_{13,9} \mathrm{O}_{1,3}\right]_{\mathrm{n}}$} & LIGNINA $^{1}$ \\
\hline Água & $\mathrm{H}_{2} \mathrm{O}$ & WATER \\
\hline Dextrose & $\mathrm{C}_{6} \mathrm{H}_{12} \mathrm{O}_{6}$ & DEXTROSE \\
\hline Sacarose & $\mathrm{C}_{12} \mathrm{H}_{22} \mathrm{O}_{11}$ & SUCROSE \\
\hline Frutose* & $\mathrm{C}_{6} \mathrm{H}_{12} \mathrm{O}_{6}-\mathrm{N} 1$ & FRUTOSE $^{1}$ \\
\hline Furfural & $\mathrm{C}_{5} \mathrm{H}_{4} \mathrm{O}_{2}$ & FURFURAL \\
\hline Hidroxi-metil-furfural & $\mathrm{C}_{5} \mathrm{H}_{4} \mathrm{O}_{2}$ & FURFURAL \\
\hline Ácido sulfúrico & $\mathrm{H}_{2} \mathrm{SO}_{4}$ & SULFUROUS-ACID \\
\hline Hidróxido de Sódio & $\mathrm{NaOH}$ & $\mathrm{NaOH}$ \\
\hline Ácido Fosfórico & $\mathrm{H}_{3} \mathrm{PO}_{4}$ & $\mathrm{H} 3 \mathrm{PO} 4$ \\
\hline Hidróxido de Cálcio* & $\mathrm{Ca}(\mathrm{OH})_{2}$ & $\mathrm{Ca}(\mathrm{OH}) 2^{1}$ \\
\hline Fosfato de Cálcio* & $\mathrm{Ca}_{3}\left(\mathrm{PO}_{4}\right)_{2}$ & $\mathrm{Ca} 3(\mathrm{PO} 4) 2^{1}$ \\
\hline Terra* & $\mathrm{SiO}_{2}$ & 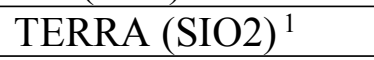 \\
\hline Xilose* & $\mathrm{C}_{5} \mathrm{H}_{10} \mathrm{O}_{5}$ & $\mathrm{XILOSE}^{1}$ \\
\hline Dióxido de enxofre & $\mathrm{SO}_{2}$ & SULFUR-DIOXIDE \\
\hline Ácido acético & $\mathrm{C}_{2} \mathrm{H}_{4} \mathrm{O}_{2}$ & ACETIC-ACID \\
\hline Enzima* & $\mathrm{CH}_{1,57} \mathrm{~N}_{0,29} \mathrm{O}_{0,31} \mathrm{~S}_{0,007}$ & ENZIMA $^{1}$ \\
\hline Levedura* & $\mathrm{CH}_{1,8} \mathrm{O}_{0,9} \mathrm{~N}_{0,145}$ & LEVEDURA $^{1}$ \\
\hline Etanol & $\mathrm{C}_{2} \mathrm{H}_{6} \mathrm{O}$ & ETHANOL \\
\hline Dióxido de Carbono & $\mathrm{CO}_{2}$ & $\mathrm{CO} 2$ \\
\hline Glicerol & $\mathrm{C}_{3} \mathrm{H}_{8} \mathrm{O}_{3}$ & GLYCEROL \\
\hline Hidrogênio & $\mathrm{H}_{2}$ & HRYDROGEN \\
\hline Ácido Succínico & $\mathrm{C}_{4} \mathrm{H}_{6} \mathrm{O}_{4}$ & SUCCINICACID \\
\hline Ácido Acético & $\mathrm{C}_{2} \mathrm{H}_{4} \mathrm{O}_{2}$ & ACETICACID \\
\hline Álcool Isoamílico & $\mathrm{C}_{5} \mathrm{H}_{12} \mathrm{O}$ & 3-M-1-C4ol \\
\hline Amônia & $\mathrm{NH}_{3}$ & AMMONIA \\
\hline
\end{tabular}

${ }^{1}$ Componentes inseridos no simulador como hipotéticos.

Tabela 2 - Composição do sorgo sacarino sujo.

\begin{tabular}{cc}
\hline Componente & $\%(\mathrm{~m} / \mathrm{m})$ \\
\hline Água & 71,07 \\
\hline Celulose & 7,72 \\
\hline Hemicelulose & 3,83 \\
\hline Lignina & 3,78 \\
\hline Sacarose & 10,00 \\
\hline Frutose & 1,09 \\
\hline Glicose & 1,91 \\
\hline Terra e outras impurezas & 0,60 \\
\hline
\end{tabular}

Fonte: Barcelos (2012), May et al.(2012) 
O modelo termodinâmico utilizado para a realização das simulações foi o Universal Quasi-Chemical - UNIQUAC. Esse modelo foi escolhido por representar com maior precisão os equilíbrios termodinâmicos dos componentes envolvidos. Seguindo a metodologia de Dias (2008) para a cana-de-açúcar, foi adotada a vazão de entrada de sorgo de 500 toneladas por hora.

\subsubsection{Operações Unitárias inseridas no simulador}

\subsubsection{Limpeza, extração e tratamento físico-químico do caldo}

Para remoção da terra, é necessária uma limpeza a seco da matéria prima antes de ser enviada para a moenda. As etapas de limpeza e extração do caldo, foram simuladas pela ferramenta Splitter. Em seguida, o caldo e o bagaço são separados e tratados separadamente.

O tratamento físico-químico do caldo seguiu o modelo proposto por Dias (2008). A fim de remover fibra e terra arrastados, o caldo passa por peneiras e hidrociclone. A operação também foi definida utilizando um Splitter.

Para o tratamento químico, o caldo passa pela adição de ácido fosfórico $85 \%$, aquecimento até $70^{\circ} \mathrm{C}$ e etapa de calagem em um tanque, representada pela Equação 1.

$$
3 \mathrm{Ca}(\mathrm{OH})_{2}+2 \mathrm{H}_{3} \mathrm{PO}_{4} \rightarrow \mathrm{Ca} 3\left(\mathrm{PO}_{4}\right)_{2}(\text { sólido })+6 \mathrm{H}_{2} \mathrm{O}
$$

O caldo calado e o reciclo do filtrado obtido no filtro de lodo do decantador são misturados, pressurizados até 2,5 bar, aquecidos a $105^{\circ} \mathrm{C}$ e desaerados com auxílio de um balão de flash atmosférico. Após este processo, o caldo segue para a etapa da decantação. $\mathrm{Na}$ entrada do decantador adiciona-se a poliacrilamida, que é o polímero floculante. Devido a sua baixa vazão, cerca de $1 \mathrm{~kg} / \mathrm{h}$, esta adição não é realizada na simulação, entretanto, seu efeito é considerado e seus benefícios incluídos nos parâmetros do decantador, definido como um Splitter.

O lodo recebe água de lavagem para reduzir as perdas de açúcares na torta e é então encaminhado para o Filtro, também definido como um Splitter, onde a torta de filtro é separada do filtrado, que é reciclado. O caldo clarificado, livre de terra, fibras e poliacrilamida, segue para a etapa de concentração (DIAS,2008).

A Tabela 3 apresenta os principais parâmetros inseridos no simulador para realização dessas etapas. 
Tabela 3 - Parâmetros inseridos no simulador para realização das etapas de limpeza, extração e tratamento da fração sacarínea (caldo).

\begin{tabular}{cc}
\hline Remoção de Terra na Limpeza & $70 \%$ \\
\hline Eficiência da Limpeza & $99,5 \%$ \\
\hline Eficiência das moendas & $97,5 \%$ \\
\hline Umidade do bagaço & $50 \%$ \\
\hline Eficiência de remoção de fibra e terra no tratamento físico & $82,1 \%$ \\
\hline Teor de fosfato no caldo após adição de $\mathrm{H}_{3} \mathrm{PO}_{4}$ & $0,03 \%(\mathrm{~m} / \mathrm{m})$ \\
\hline Quantidade de leite de cal adicionada & $0,9 \mathrm{~kg} /$ ton matéria-prima \\
\hline Conversão da reação química 1 & $100 \%$ \\
\hline Separação de sólidos no decantador & $100 \%$ \\
\hline Teor de sacarose na torta & $1,6 \%$ \\
\hline Vazão da água de Lavagem & $70 \mathrm{~kg} /$ ton matéria-prima \\
\hline
\end{tabular}

\subsubsection{Tratamento do bagaço}

Para remoção da terra, é necessária uma limpeza a seco da matéria prima antes de ser enviada para a moenda. As etapas de limpeza e extração do caldo foram simuladas pela ferramenta Splitter. Em seguida, o caldo e o bagaço são separados e tratados separadamente.

Os produtos de interesse, estudados nos pré-tratamentos, foram a xilose, o ácido acético e o furfural. O furfural e o $\mathrm{HMF}$, responsáveis pela degradação das pentoses e hexoses inibindo a fermentação, são produtos da reação de desidratação da xilose e glicose. As reações representadas pela Equação 2 a 4 representam a solubilização da hemicelulose a xilose e ácido acético e conversão da xilose em furfural, respectivamente

$$
\begin{aligned}
& {\left[\mathrm{C}_{5} \mathrm{H}_{8} \mathrm{O}_{4}\right]_{n}+\mathrm{H}_{2} \mathrm{O} \rightarrow \mathrm{C}_{5} \mathrm{H}_{10} \mathrm{O}_{5}} \\
& {\left[\mathrm{C}_{5} \mathrm{H}_{8} \mathrm{O}_{4}\right]_{n}+\mathrm{H}_{2} \mathrm{O} \rightarrow 2,5 \mathrm{C}_{2} \mathrm{H}_{4} \mathrm{O}_{2}} \\
& \mathrm{C}_{5} \mathrm{H}_{10} \mathrm{O}_{5} \rightarrow \mathrm{C}_{5} \mathrm{H}_{4} \mathrm{O}_{2}+3 \mathrm{H}_{2} \mathrm{O}
\end{aligned}
$$

\subsection{Pré-tratamento com ácido diluído e alcalino}

O pré tratamento com ácido diluído possui muitos benefícios quando comparado a sua forma concentrada. Ele reduz a formação de interferentes e diminuí a incidência de corrosão 
nos equipamentos (SUN e CHENG, 2002). De acordo com Barcelos (2012) o pré tratamento alcalino deve ser realizado seguido do pré tratamento com ácido diluído, pois ele remove a lignina aumentando os rendimentos da hidrólise enzimática.

Nesta etapa, o fluxo mássico do bagaço processado foi padronizado para 152,53 ton.h${ }^{1}$ e umidade de $50 \%$. O bagaço e o ácido diluído são misturados, pressurizados e aquecido e levados ao reator, representado no simulador como reator de conversão. Após a reação, o material segue para o sistema de separação, onde é lavado e filtrado obtendo-se uma pasta de sólidos, que contém lignina e celulose e um licor de pentoses.

Em seguida, é realizado o pré tratamento alcalino, ou etapa de deslignificação, seguindo os parâmetros apresentados por Barcelos (2012). A razão de sólidos e solvente utilizada foi de $1 / 21 \mathrm{~g} \mathrm{~mL}^{-1}$ e a concentração da solução de $\mathrm{NaOH}$ foi $0,25 \mathrm{M}$. A solubilização foi conduzida a temperatura de $120{ }^{\circ} \mathrm{C}$. O material foi majoritariamente dissolvido devido ao alto rendimento das reações de solubilização. O material solubilizado e o solvente são separadas da pasta celulósica por filtração. Esse processo de separação foi simulado em uma única etapa através da ferramenta simple solid separator, disponível no software. A Tabela 4 apresenta os principais parâmetros inseridos no simulador para o prétratamento ácido.

Tabela 4 - Parâmetros inseridos no simulador para o pré-tratamento ácido.

\begin{tabular}{cc}
\hline Relação sólido-líquido & $1 / 4,52 \mathrm{~g} / \mathrm{mL}$ \\
\hline Concentração do ácido sulfúrico & $1,39 \mathrm{v} / \mathrm{v}$ \\
\hline Temperatura da reação & $120^{\circ} \mathrm{C}$ \\
\hline Pressão de operação do reator & $2 \mathrm{bar}$ \\
\hline Conversão da hemicelulose - xilose (Equação 2) & $77 \%$ \\
\hline Conversão da hemicelulose - ácido acético (Equação 3) & $17 \%$ \\
\hline Conversão da xilose - furfural (Equação 4) & $0,5 \%$ \\
\hline
\end{tabular}

Fonte: Dias (2008); Barcelos (2012)

\subsection{Pré-tratamento de explosão a vapor}

Este pré tratamento ocorre colocando-se o vapor pressutizado em contato com o bagaço, durante um determinado tempo, até que subitamente o material é depressurizado, acarretando na solubilização da hemicelulose (SIPOS et al., 2008). Alguns autores apresentam a utilização do dióxido de enxofre como catalizador nesse pré tratamento (ALVIRA et al., 2010).

Após a reação, o material é despressurizado e enviado para um ciclone, onde ocorre a separação da fração sólida residual e do material diluído. Para fins práticos, o procedimento adotou a descompressão até a pressão ambiente e separação do material em um tanque flash (BERECHE, 2011). A Tabela 5 apresenta os parâmetros envolvidos nessa etapa do processo. 
Tabela 5 - Parâmetros Inseridos para o pré-tratamento de Explosão a Vapor.

\begin{tabular}{cc}
\hline Temperatura da reação $\left({ }^{\circ} \mathrm{C}\right)$ & 200 \\
\hline Pressão do reator $(\mathrm{bar})$ & 12,5 \\
\hline Relação sólido/vapor $(\mathrm{kg} / \mathrm{kg})$ & $1 / 0,55$ \\
\hline Umidade do bagaço $(\mathrm{m} / \mathrm{m})$ & $50 \%$ \\
\hline Quantidade de catalisador $(\mathrm{m} / \mathrm{m}$ umidade) & $2 \%$ \\
\hline Conversão hemicelulose - xilose & $61 \%$ \\
\hline Conversão hemicelulose - ácido acético & $12 \%$ \\
\hline Conversão xilose - furfural & $5,5 \%$ \\
\hline Fonte: Sipos et al. (2009); Bereche $(2011)$ &
\end{tabular}

\subsection{Pré-tratamento Hidrotérmico}

O pré tratamento hidrotérmico se baseia em utilizar água no estado líquido, pressurizada e em altas temperaturas. (ALVIRA et al., 2010). A temperatura de operação varia em torno de $210^{\circ} \mathrm{C}$ e o tempo de operação varia entre 10 a $30 \mathrm{~min}$. (DOGARIS et al., 2009).

Esse pré tratamento possui destaque no contexto mundial devida a não utilização de produtos químico, como ácido sulfúrico, amônia e até mesmo dióxido de enxofre (YU et al., 2011). Em contrapartida, o pré tratamento hidrotérmico é um processo que requer grandes quantidades de água e energia (ALVIRA et al., 2010).

Para a simulação desse pré tratamento, foram considerados os parâmetros obtidos no procedimento realizado por Dogaris et. al., (2009) A Tabela 6 apresenta os principais parâmetros utilizados nessa etapa.

Tabela 6 - Parâmetros Inseridos no Simulador para o Pré Tratamento Hidrotérmico.

\begin{tabular}{cc}
\hline Temperatura da reação $\left({ }^{\circ} \mathrm{C}\right)$ & 210 \\
\hline Relação sólido líquido $(\mathrm{m} / \mathrm{m})$ & 6,7 \\
\hline Pressão (bar) & 21 \\
\hline Conversão hemicelulose - xilose & $75 \%$ \\
\hline Conversão hemicelulose - ácido acético & $8,3 \%$ \\
\hline Conversão xilose - furfural & $2,66 \%$ \\
\hline
\end{tabular}

Fonte: Dogaris, et al. 2009

\subsection{Hidrólise Enzimática}

A hidrólise utilizando a enzima apropriada representa o método mais eficiente em 
liberar açúcares fermentescíveis a partir de materiais celulósicos (TALEBNIA et al., 2010). Quando realizada em escala experimental, a quantidade de sólidos processada nessa etapa pode ser baixa. Entretanto, para operações industriais, o teor de sólidos deve ser maior para evitar gastos energéticos na etapa de concentração do caldo (DIAS, 2011).

Esse procedimento se baseou na simulação da hidrólise enzimática realizada por Albarelli (2013) e nos dados obtidos por Barcelos (2012), Dogaris et. al. (2009) e Sipos et al. (2009). Segundo Dias (2011) a hidrólise deve ser conduzida sob maiores teores de sólidos, pois, mesmo que as conversões sejam inferiores, evitam-se gastos energéticos na etapa de concentração do caldo. Após a reação o material sólido não reagido foi separado do licor de hexoses que foi conduzido para etapa de fermentação. Os parâmetros inseridos no simulador para essa etapa estão descritos na Tabela 7.

Tabela 7 - Parâmetros Inseridos no Simulador para Hidrólise Enzimática.

\begin{tabular}{cc}
\hline Carga enzimática celulase (FPU/g de biomassa) & 15 \\
\hline Teor de sólidos no reator $\%(\mathrm{~m} / \mathrm{m})$ & $10 \%$ \\
\hline Temperatura da reação $\left({ }^{\circ} \mathrm{C}\right)$ & 50 \\
\hline Rendimento celulose - glicose (Ácido diluído) & $82 \%$ \\
\hline Rendimento celulose - glicose (Explosão a vapor) & $61,1 \%$ \\
\hline Rendimento celulose - glicose (Hidrotérmico) & $90 \%$ \\
\hline
\end{tabular}

Fonte: Dias (2011), Albarelli (2013), Barcelos (2012), Dogaris et. al. (2009) e Sipos et al. (2009).

\subsubsection{Concentração e esterilização}

A corrente proveniente do caldo é dividida em duas partes, uma delas é misturada a corrente da fração lignocelulósica e então é levada para etapa de concentração em um evaporador de 4 efeitos, onde é concentrada a $25^{\circ}$ Brix. Esta se mistura com a outra parte da corrente do caldo, gerando um mosto com concentração de $22^{\circ}$ Brix.

Não há uma operação unitária correspondente ao evaporador de múltiplo efeito no simulador, e por isto, utiliza-se um sistema com separador, válvula e trocador de calor, apresentado por Dias (2008). A próxima etapa é a esterilização onde esta corrente é aquecida até $130{ }^{\circ} \mathrm{C}$ e então resfriada a $32{ }^{\circ} \mathrm{C}$, obtendo-se o Mosto, que é a matéria prima da fermentação. A Tabela 8 apresenta a pressão e temperatura no evaporador de múltiplos efeitos.

Tabela 8 - Pressão e temperatura no evaporador de múltiplo efeito.

\begin{tabular}{ccc}
\hline Efeito & Pressão(bar) & Temperatura $\left({ }^{\circ} \mathrm{C}\right)$ \\
\hline $1^{\circ}$ Efeito & 1,681 & 115 \\
\hline $2^{\circ}$ Efeito & 1,354 & 108,6 \\
\hline $3^{\circ}$ Efeito & 0,500 & 81,87 \\
\hline $4^{\circ}$ Efeito & 0,300 & 64,6 \\
\hline
\end{tabular}




\subsubsection{Fermentação e Destilação}

Os açúcares podem então ser fermentados. A levedura mais comum nesse processo é a Saccharomyces cerevisiae, capaz de converter hexoses em etanol (CARDONA et. al., 2010). A fermentação foi simulada em uma temperatura de $25^{\circ} \mathrm{C}$ e a levedura foi utilizada de forma a completar $25 \%$ do volume do reator (DIAS, 2008). Do ponto de vista reacional, primeiramente a sacarose é invertida a glicose e frutose, com conversão de $100 \%$, conforme a Equação 6. Após isto, com a conversão das hexoses, o etanol é produzido, com conversão de $85 \%$, seguindo a Equação 7 .

$$
\begin{aligned}
& \left.\mathrm{C}_{12} \mathrm{H}_{22} \mathrm{O}_{11}+\mathrm{H}_{2} \mathrm{O} \rightarrow \mathrm{C}_{6} \mathrm{H}_{12} \mathrm{O}_{6}(\text { Glicose })+\mathrm{C}_{6} \mathrm{H}_{12} \mathrm{O}_{6} \text { (Frutose }\right) \\
& \mathrm{C}_{6} \mathrm{H}_{12} \mathrm{O}_{6} \rightarrow 2 \mathrm{C}_{2} \mathrm{H}_{5} \mathrm{OH}+2 \mathrm{CO}_{2}
\end{aligned}
$$

Outras reações ocorrem paralelamente no reator, com a formação de diversos subprodutos. A Equação 8 é a formação de glicerol com seletividade de 2,67\%. A Equação 9 é formação de ácido succínico, com seletividade de 0,29\%. A Equação 10 é formação de ácido acético, com seletividade de 1,19\% e a Equação 11 é formação de ácido iso-amílico com seletividade de $3,1 \times 10^{-4 \%}$. A Equação 12 é o crescimento da levedura, tem seletividade de $1,37 \%$.

$$
\begin{aligned}
& \mathrm{C}_{6} \mathrm{H}_{12} \mathrm{O}_{6}+4 \mathrm{H}^{+} \rightarrow 2 \mathrm{C}_{3} \mathrm{H}_{8} \mathrm{O}_{3} \\
& \mathrm{C}_{6} \mathrm{H}_{12} \mathrm{O}_{6}+2 \mathrm{H}_{2} \mathrm{O} \rightarrow \mathrm{C}_{4} \mathrm{H}_{6} \mathrm{O}_{4}+2 \mathrm{CO}_{2}+10 \mathrm{H}^{+}+10 e^{-} \\
& \mathrm{C}_{6} \mathrm{H}_{12} \mathrm{O}_{6}+2 \mathrm{H}_{2} \mathrm{O} \rightarrow 2 \mathrm{C}_{2} \mathrm{H}_{4} \mathrm{O}_{2}+2 \mathrm{CO}_{2}+8 \mathrm{H}^{+}+8 e^{-} \\
& \mathrm{C}_{6} \mathrm{H}_{12} \mathrm{O}_{6} \rightarrow 0,795 \mathrm{C}_{5} \mathrm{H}_{12} \mathrm{O}+2,025 \mathrm{CO}_{2}+1,155 \mathrm{H}_{2} \mathrm{O}+0,15 \mathrm{H}^{+}+0,15 e^{-} \\
& 0,1485 \mathrm{C}_{6} \mathrm{H}_{12} \mathrm{O}_{6}+0,145 \mathrm{NH}_{4}^{+}+0,1087 \mathrm{CO}_{2} \rightarrow \mathrm{CH}_{1,8} \mathrm{O}_{0,9} \mathrm{~N}_{0,145}+0,2087 \mathrm{H}_{2} \mathrm{O}+ \\
& 0,145 H^{+}
\end{aligned}
$$


A levedura deve ser centrifugada e recuperada e reciclada para o sistema. Esse processo de reciclagem da levedura não foi adotado nessa simulação, visto que essa levedura pode ser destinada a outros processos, como por exemplo a fabricação de ração.

O sistema de destilação mais utilizado nas usinas é constituído por 4 colunas de destilação (DIAS, 2008). Essas colunas são denominadas colunas A, A1, B e D. O vinho, previamente aquecido, entra na coluna A1, cuja função é purificar o vinho de gases de alta volatilidade obtidos na etapa de fermentação (BERECHE, 2011). O produto de fundo da coluna A1, entra no topo da coluna A, denominada esgotadora, e produz a vinhaça e a flegma na fase vapor, com teor alcoólico de cerca de $44 \%$ em massa. Essa flegma é alimentada no fundo da coluna B, onde obtêm-se o etanol hidratado e o vinho, com baixo teor alcoólico (DIAS, 2008). Finalmente a coluna D tem a função de separar os gases do material alcoólico residual, que deve ser alimentado também a coluna B. Os parâmetros utilizados na simulação da destilação estão apresentados na Tabela 9.

Tabela 9 - Parâmetros Inseridos no Simulador para a Destilação.

\begin{tabular}{cc}
\hline Coluna A & Valor \\
\hline Número de pratos & 18 \\
\hline Pressão no topo $(\mathrm{kPa})$ & 139,3 \\
\hline Pressão no fundo $(\mathrm{kPa})$ & 152,5 \\
\hline Posição de retirada de vapor de flegma & 17 \\
\hline Fração mássica de etanol na vinhaça & 0,0002 \\
\hline Recuperação de etanol no vapor de flegma (\%) & 76 \\
\hline Coluna A1 & Valor \\
\hline Número de pratos & 8 \\
\hline Pressão no topo $(\mathrm{kPa})$ & 136,3 \\
\hline Pressão no fundo $(\mathrm{kPa})$ & 139,3 \\
\hline Coluna D & Valor \\
\hline Número de pratos & 6 \\
\hline Pressão no topo (kPa) & 133,8 \\
\hline Pressão no fundo $(\mathrm{kPa})$ & 136,3 \\
\hline Temperatura no condensador $\left({ }^{\circ} \mathrm{C}\right)$ & 35 \\
\hline Fração de álcool de segunda reciclada na coluna D & 0,99 \\
\hline Coluna B & \\
\hline Número de pratos & 116,0 \\
\hline Pressão no topo (kPa) & 135,7 \\
\hline Pressão no fundo $(\mathrm{kPa})$ & 23 \\
\hline Posição de alimentação de vapor de flegma & 94 \\
\hline Fração mássica de etanol no etanol hidratado (\%) &
\end{tabular}

Fonte: Dias (2008) 


\subsection{Análise econômica}

Todos os equipamentos envolvidos no processo de simulação foram dimensionados e seus custos determinados pelo software Aspen Hysys 8.8. Utilizou-se o custo total dos equipamentos para estimar o custo capital da planta. Calcularam-se as quantidades de matéria-prima e as utilidades necessárias, através do balanço de massa e energia do processo. O custo de fabricação e instalação da planta foi chamado custo fixo de investimento (CFI), enquanto o custo necessário para operação da planta foi chamado de capital de operação (CO). A soma dos custos fixo de investimento e do capital de operação da planta é conhecido como capital total de investimento (CTI).

Para avaliação dos custos envolvidos no processo, foram inseridos no simulador o preço dos materiais utilizados. Os valores utilizados foram ajustados para o ano corrente. Esses valores estão disponíveis na Tabela 10. Dessa forma, o custo da produção foi obtido e utilizado no fluxo de caixa para determinar a rentabilidade do processo.

Tabela 10 - Custos dos Reagentes e Produtos.

\begin{tabular}{cc}
\hline Material & Preço \\
\hline Etanol Hidratado $^{1}$ & $0.5484(\mathrm{US} \$ / \mathrm{L})$ \\
\hline Ácido Sulfúrico $^{2}$ & $0.1(\mathrm{US} \$ / \mathrm{kg})$ \\
\hline Enzima $^{2}$ & $0.16(\mathrm{US} \$ / \mathrm{kg})$ \\
\hline Hidróxido de Sódio $^{2}$ & $0.26(\mathrm{US} \$ / \mathrm{kg})$ \\
\hline Dióxido de Enxofre $^{3}$ & $0,4(\mathrm{US} \$ / \mathrm{kg})$ \\
\hline Ácido Fosfórico $^{3}$ & $0,45(\mathrm{US} \$ / \mathrm{kg})$ \\
\hline Cal $^{4}$ & $0,04(\mathrm{US} \$ / \mathrm{kg})$ \\
\hline Sorgo Sacarino $^{5}$ & $21,07(\mathrm{US} \$ / \mathrm{ton})$ \\
\hline
\end{tabular}

Fonte: ESALQ (2016); Dias (2011); ICIS (2016); Alibaba(2016);Junqueira (2015)

Realizou-se então uma análise de fluxo de caixa descontado a fim de se obter o minimum sale price (MSP) da planta. Isto é, o menor preço pelo qual o produto pode ser vendido, de forma que a produção seja lucrativa. Para isso, o custo capital deve ser analisado por ano, usando o fator de recuperação de capital (CRF). As equações para o cálculo destes parâmetros são encontrados nas Equação 13 e 14.

$$
C R F=i(1+i) n /[(1+i) n-1]
$$


Na equação do CRF, i é a taxa anual de retorno desejada e $n$ é o tempo de vida da planta. Definiu-se i igual a $20 \%$ e $n$ igual a 20 anos.

Assumiu-se também que a planta operará de maneira contínua e no estado estacionário durante 8760 horas por ano. O método de depreciação foi considerado linear, com valor residual de $20 \%$ do custo capital inicial e taxa de imposto de $40 \%$.

\subsection{Variação paramétrica}

A análise de sensibilidade paramétrica foi realizada para observar o efeito de alguns parâmetros no preço de produção. $O$ teor de sólidos na entrada da planta para cada pré tratamento foi diminuído em $30 \%$ do valor original (Caso A). Uma nova análise econômica foi realizada para cada pré tratamento e um novo valor de MSP foi calculado. Da mesma forma, o teor de sólidos foi aumentado em $30 \%$ e uma nova análise econômica foi feita (Caso B).

\section{RESULTADOS E DISCUSSÕES}

\subsection{Simulações}

Todas as etapas acima descritas, para obtenção do etanol de primeira e segunda geração, foram simuladas utilizando o Aspen HYSYS, conforme descrito no item 2 Materiais e Métodos, e estão representadas a seguir. As Figuras 1, 5,6 e 7 foram comuns a todas as simulações.

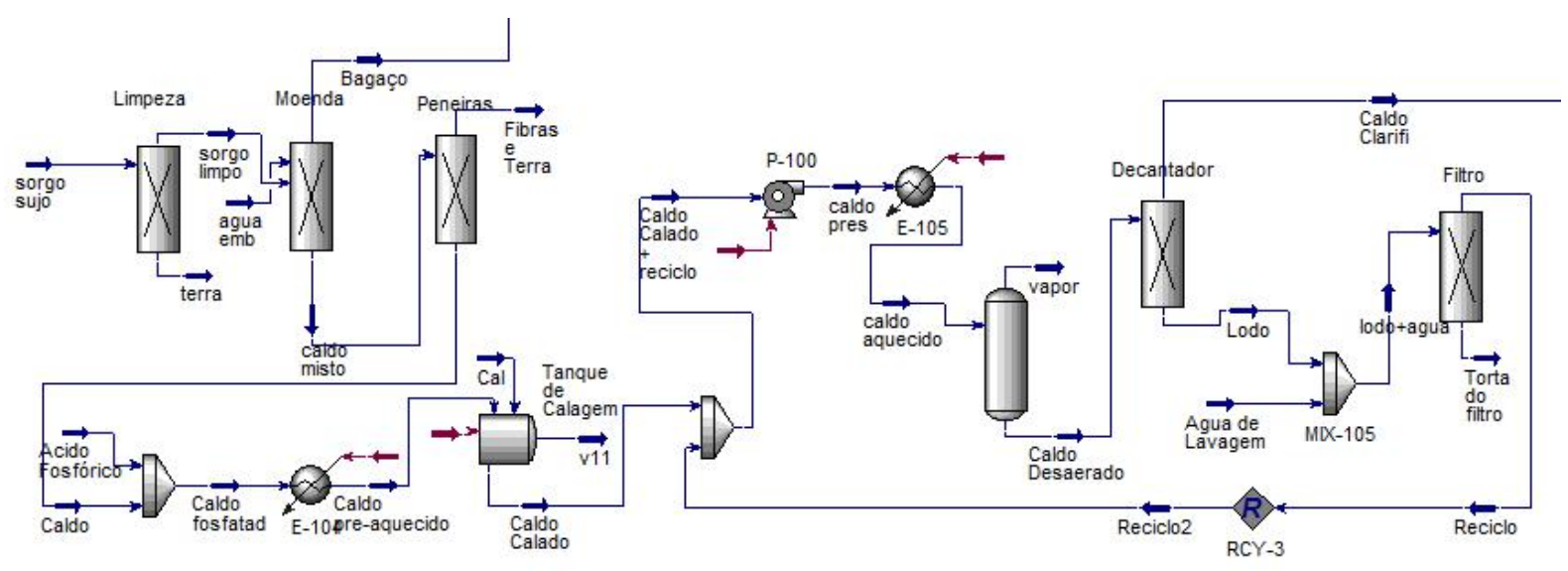

Figura 1 - Limpeza, Extração, Tratamento da Fração Sacarínea- Caldo. 


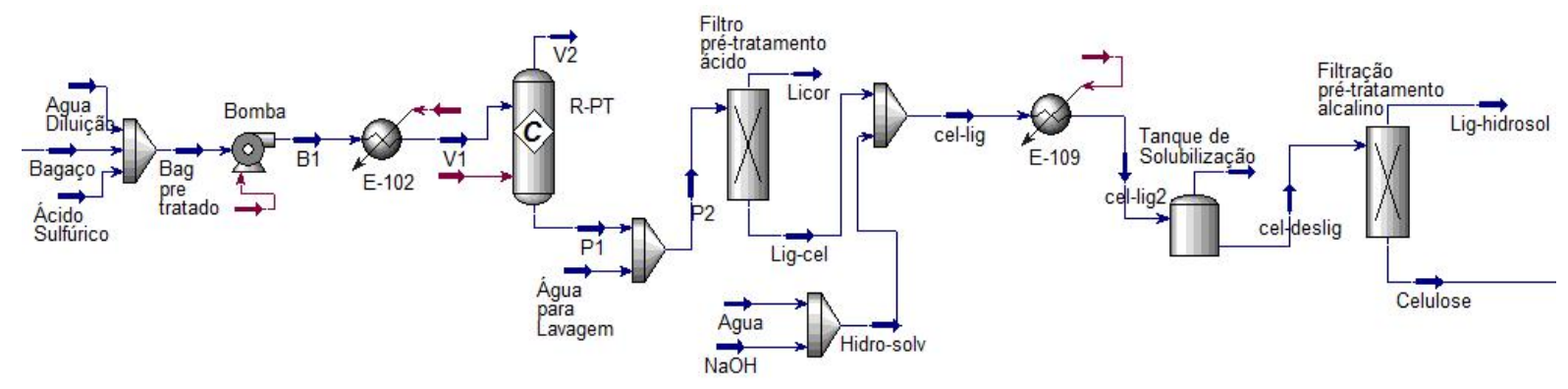

Figura 2 - Representação da Simulação com Pré-Tratamento com Ácido Diluído e Alcalino.

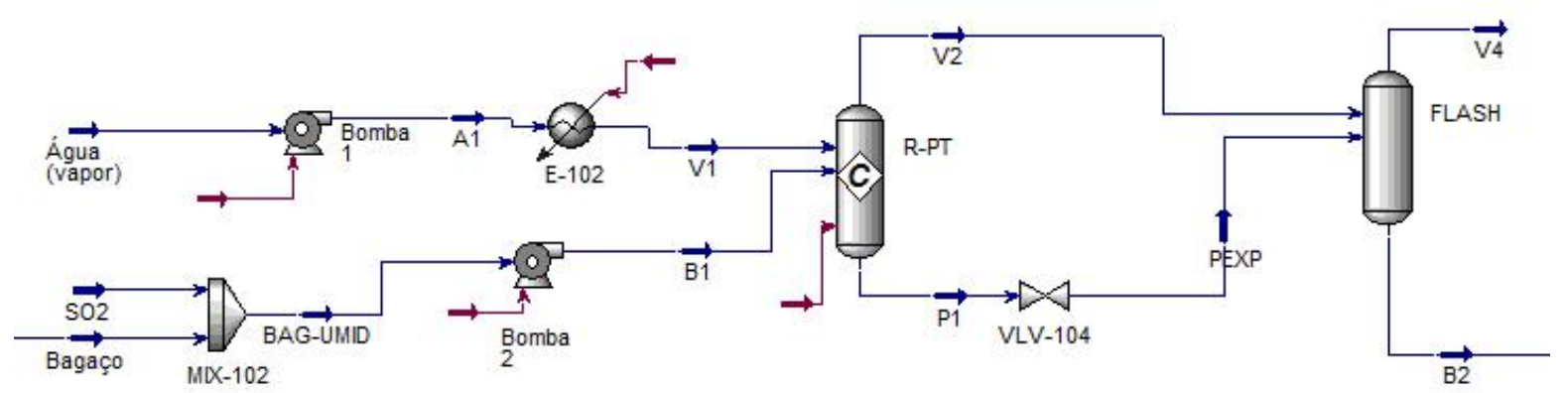

Figura 3 - Representação da Simulação com Explosão a Vapor.

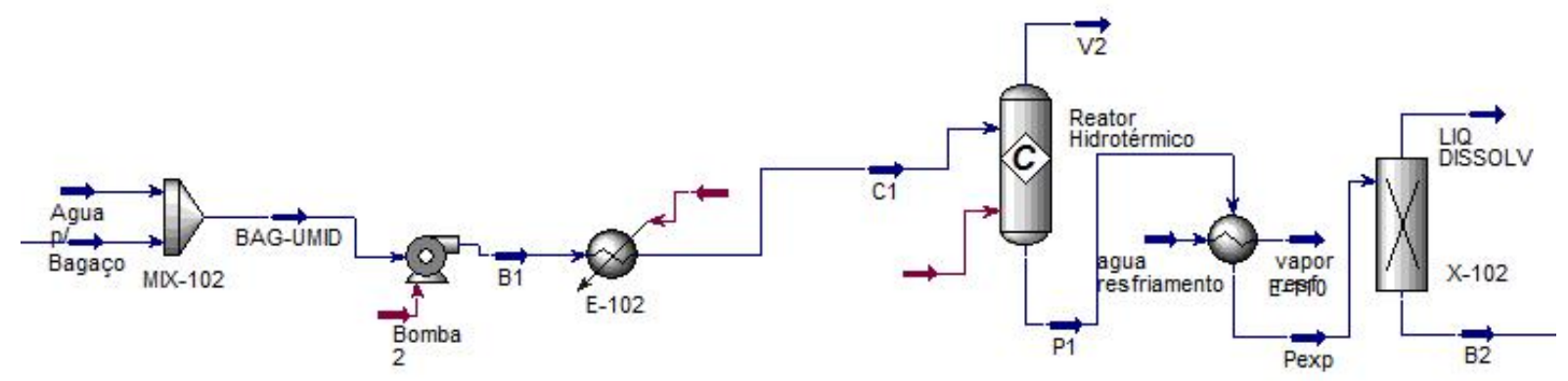

Figura 4 - Representação da Simulação com Hidrotérmico. 


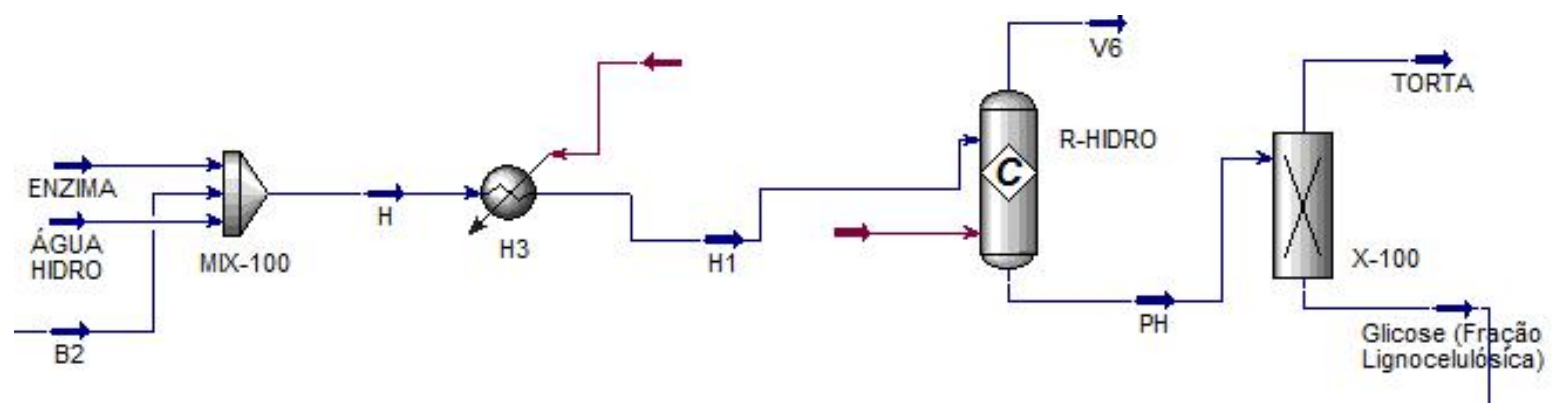

Figura 5 - Representação da Simulação da Hidrólise Enzimática.

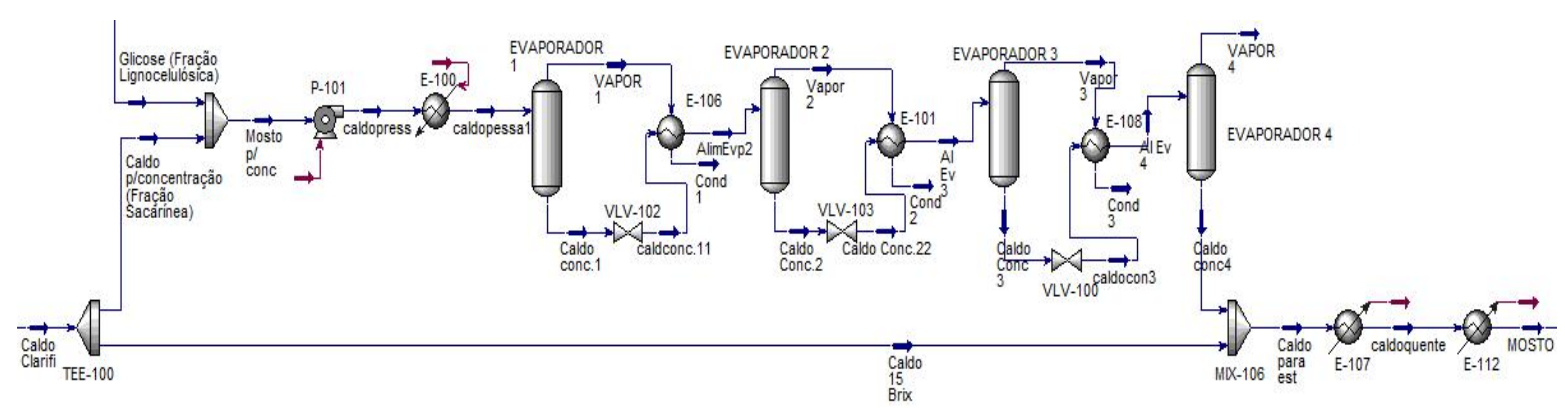

Figura 6 - Mistura das correntes tratadas do caldo e bagaço, Concentração e Esterilização.

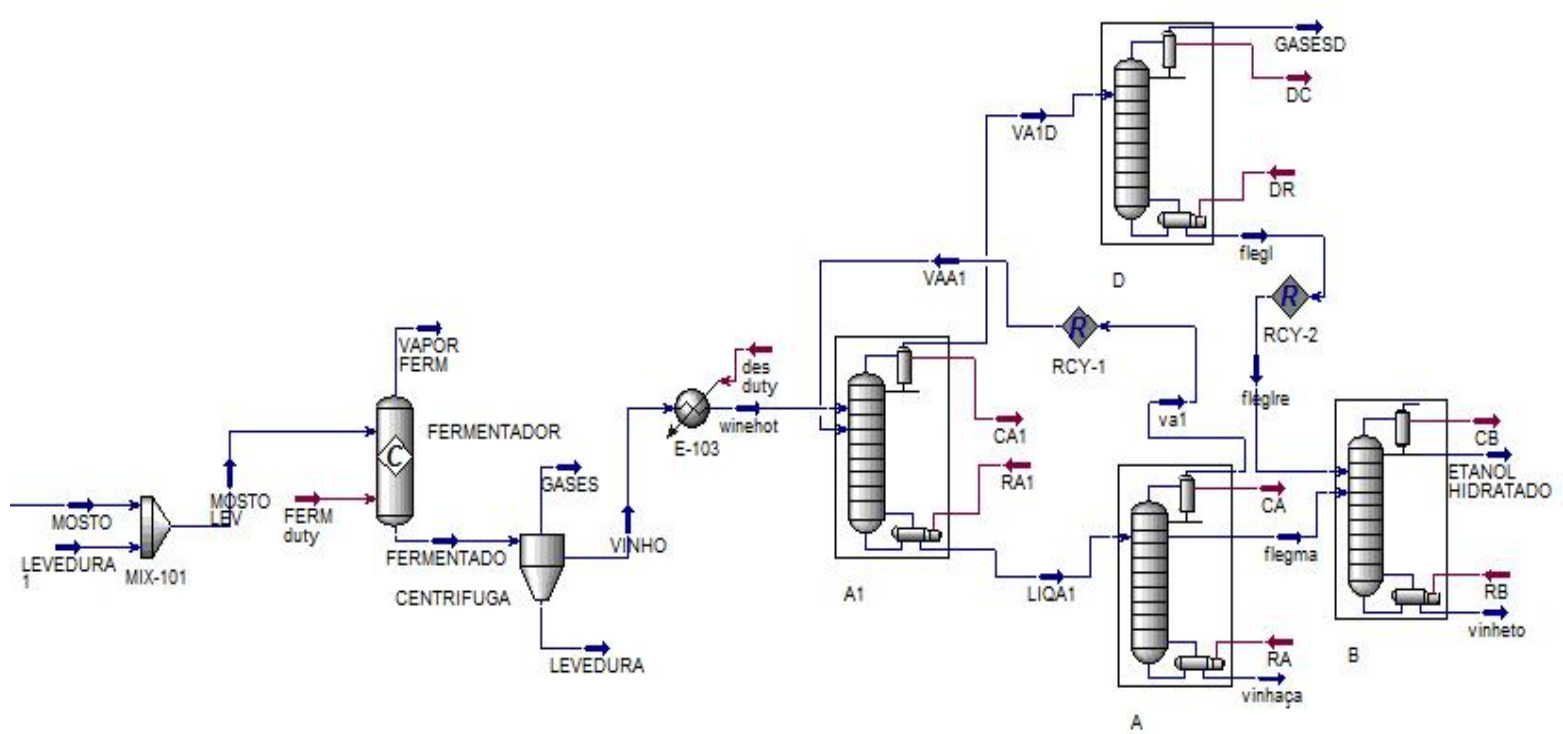

Figura 7 - Fermentação e Destilação. 


\subsubsection{Produção integrada de etanol de primeira e segunda geração utilizando o pré-tratamento ácido diluído e alcalino}

Após a simulação, estima-se uma produção anual de 408 mil toneladas de etanol e o custo operacional anual de US\$ 489,8 milhões. A Figura 8 mostra a distribuição desse valor onde a maior parte dos gastos operacionais está relacionada as utilidades quentes e matéria prima. Em relação às utilidades, esses gastos são resultado da utilização de evaporadores para concentração do caldo na etapa de pré fermentação e do sistema de destilação para separação do etanol.

Com relação a matéria prima, os custos devem-se a utilização de grande quantidade de $\mathrm{NaOH}$ para o pré tratamento alcalino, necessário após o pré tratamento ácido e a utilização de enzimas, que ainda possuem um custo elevado para aplicações industriais (ALBARELLI, 2013). Alternativas para utilização do solvente nesse processo devem ser estudadas para que sejam reduzidos os custos operacionais com matéria prima.

Na Figura 9 é possível observar a distribuição do custo de instalação dessa planta. $\mathrm{O}$ custo capital, é de US\$ 83,3 milhões e a maior parte está distribuída para compra de equipamentos, contingência e tubulação e contingencia.

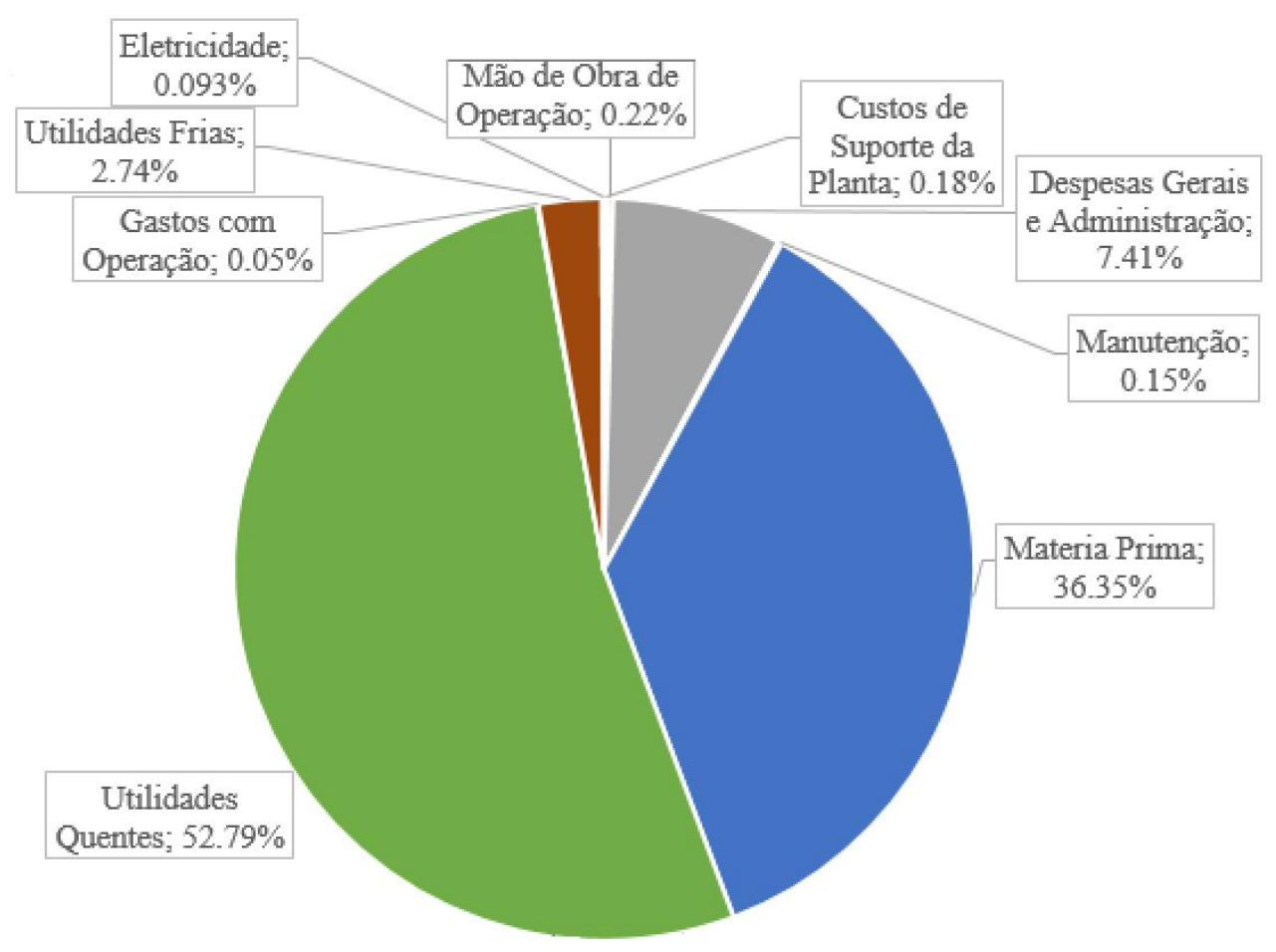

Figura 8 - Distribuição dos Custos Operacionais da Planta com Ácido Diluído. 


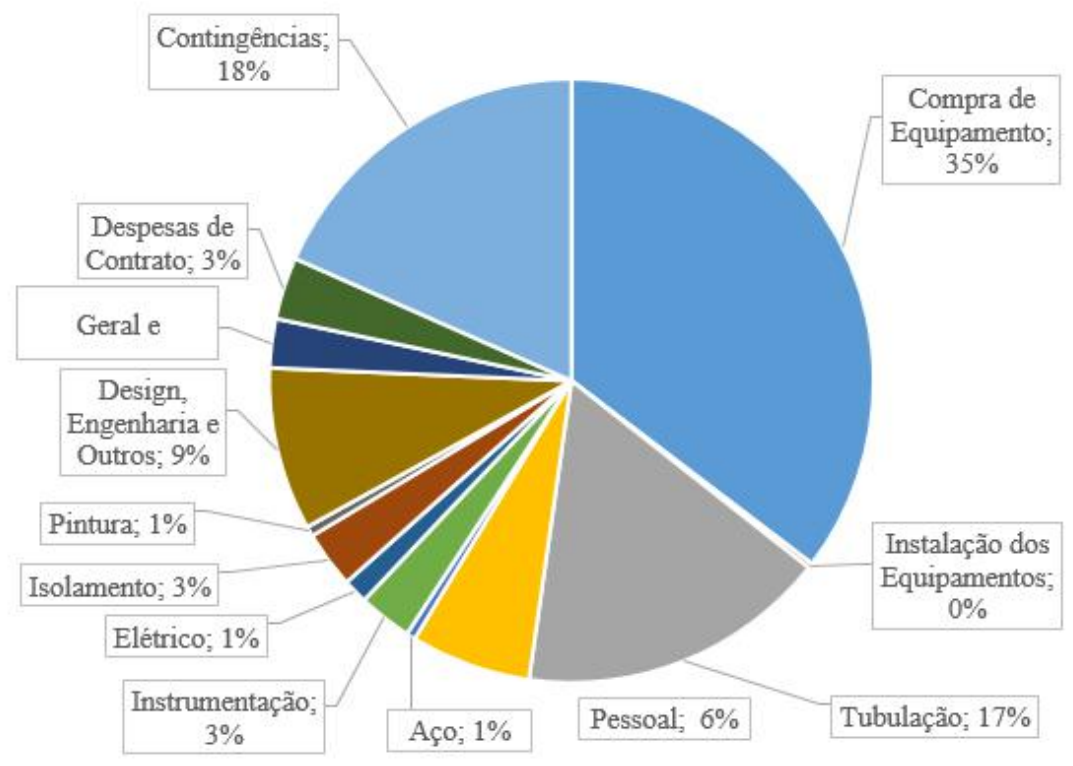

Figura 9 - Distribuição do Custo Capital do Projeto com Ácido Diluído.

\subsubsection{Produção integrada de etanol de primeira e segunda geração utilizando o pré-tratamento de explosão a vapor}

A produção anual de etanol estimada a partir dessa tecnologia é de 372 mil toneladas por ano. Esse valor é cerca de $23 \%$ menor do que a produção integrada utilizando o pré tratamento ácido e pode ser justificado pela menor solubilização da hemicelulose na etapa inicial da produção de etanol de segunda geração.

Essa produção possui o custo operacional de US\$ 489,6 milhões por ano. A representação da distribuição desse valor pode ser vista na Figura 10. A maior parcela desse valor está concentrada nas utilidades quentes, que compõe $66 \%$ do valor operacional. Isso deve-se a grande quantidade de energia envolvida nas etapas de concentração do caldo e sistema de destilação, além de grande demanda energética para etapa de explosão a vapor durante o pré tratamento. Nesse processo os gastos com matéria prima compõem $24 \%$ do valor operacional, e esse valor é devido a utilização de enzimas para etapa de hidrólise, produtos químicos para o tratamento do caldo e catalisadores que são necessários para etapa de explosão a vapor.

O custo capital total dessa planta é de US\$ 93,8 milhões e a maior parte está distribuída para compra de equipamentos, tubulação e contingência, como pode ser observado na Figura 11. O valor de instalação dessa planta é superior ao valor necessário para a que faz utilização do pré-tratamento com ácido diluído, devido a maior complexidade dos equipamentos envolvidos. 


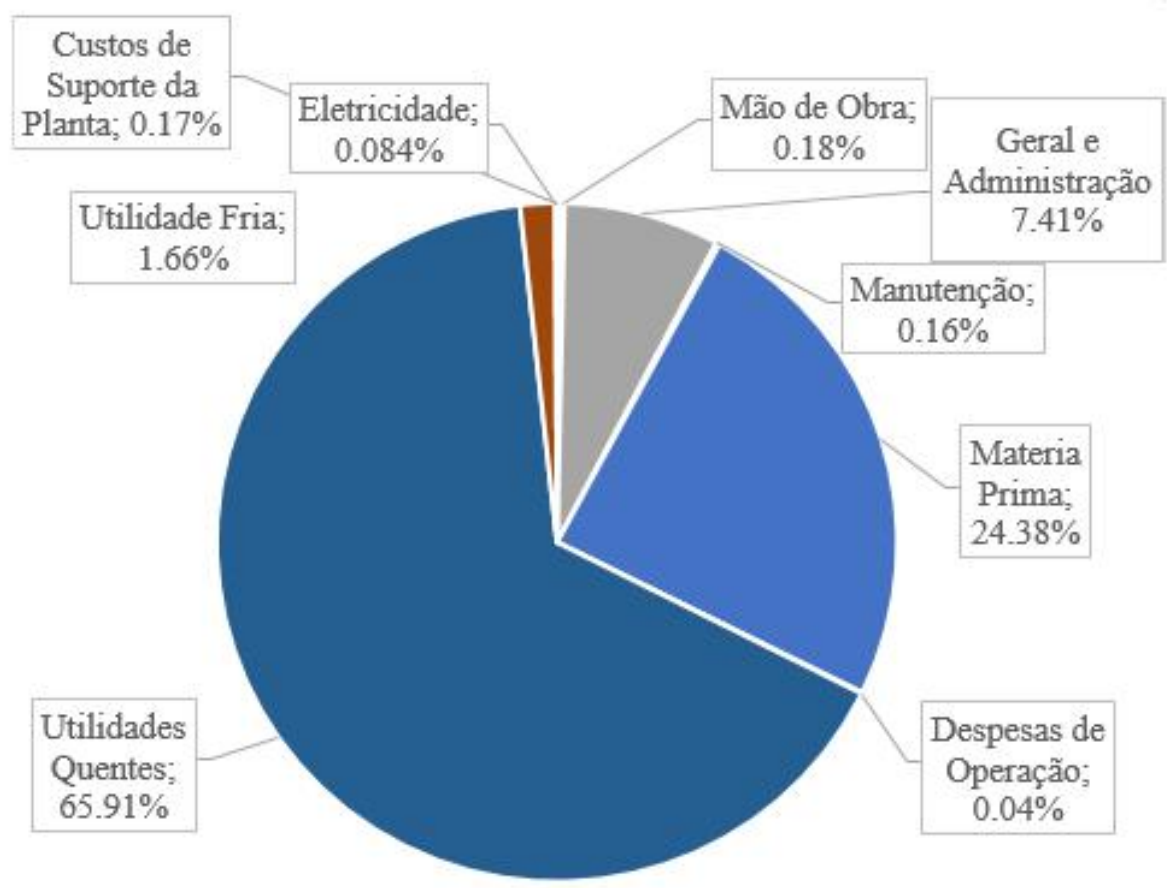

Figura 10- Distribuição dos Custos Operacionais da Planta com Explosão a Vapor.

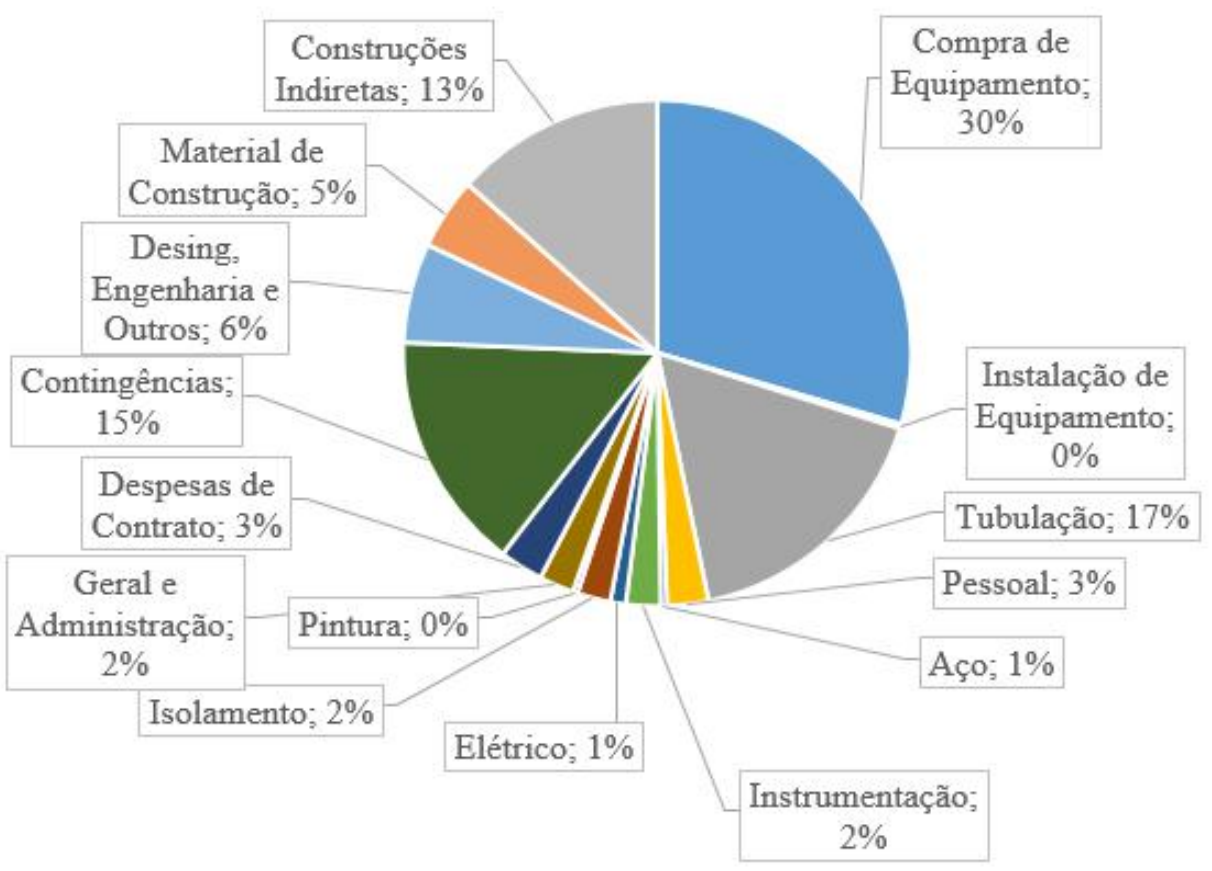

Figura 11 - Distribuição do Custo Capital do Projeto com Explosão a Vapor. 


\subsubsection{Produção integrada de etanol de primeira e segunda geração utilizando o pré-tratamento hidrotérmico}

Utilizando essa tecnologia, atinge-se a produção anual de 420 mil toneladas de etanol por ano. Esse valor é superior a todos os pré-tratamentos até aqui apresentados.

O custo operacional anual de produção é de US\$ 488,7 milhões. Esse valor é superior ao custo operacional das outras produções apresentadas anteriormente. De acordo com a Figura 12, que mostra a distribuição desse valor, a maior parte dos gastos são com utilidades quentes, $66 \%$, devido as utilidades necessárias para concentração do caldo e sistema de destilação, e também para etapa do pré tratamento, onde há grande demanda energética.

Os gastos com matéria prima são de $22 \%$, valor inferior aos outros processos, devido a não utilização de catalisadores para o pré-tratamento hidrotérmico. Todavia, há uma grande contribuição para os custos operacionais pela utilização de enzimas e matérias primas para tratamento do caldo.

O custo capital total dessa planta é de US\$ 91,9 milhões e a maior parte está distribuída para compra de equipamentos, tubulação e contingência, como pode ser observado na Figura 13. O valor de instalação dessa planta é superior ao que utiliza pré tratamento ácido, porém inferior ao pré-tratamento de explosão a vapor.

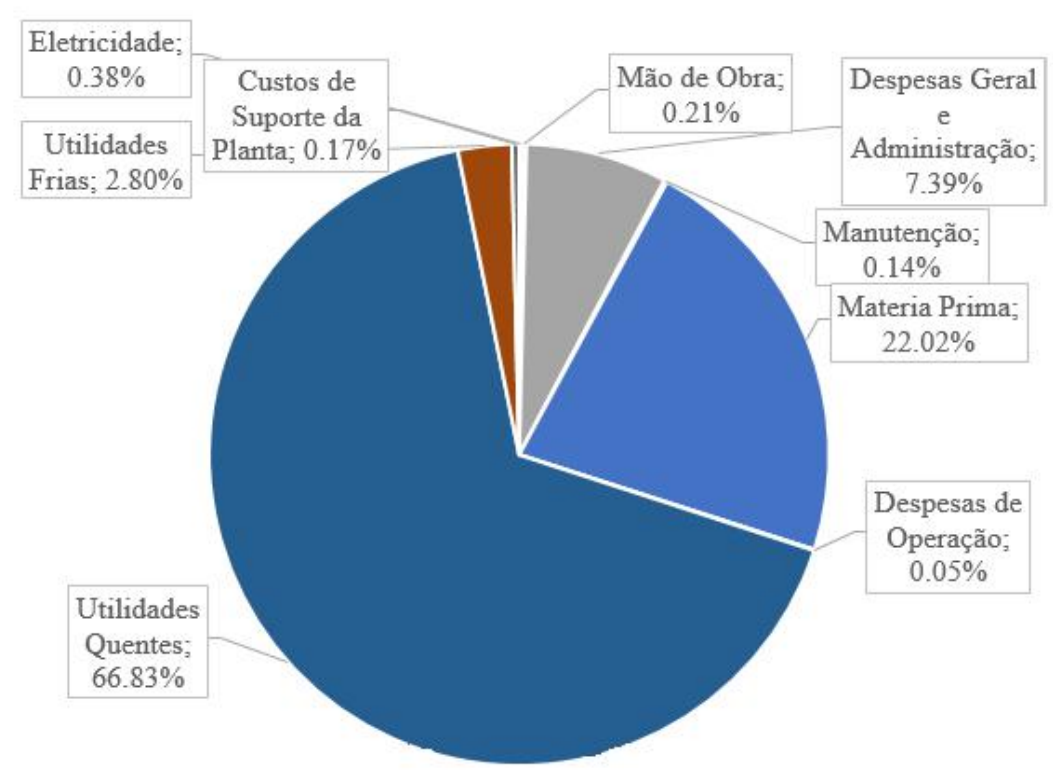

Figura 12 - Distribuição dos Custos Operacionais da Planta com Hidrotérmico. 


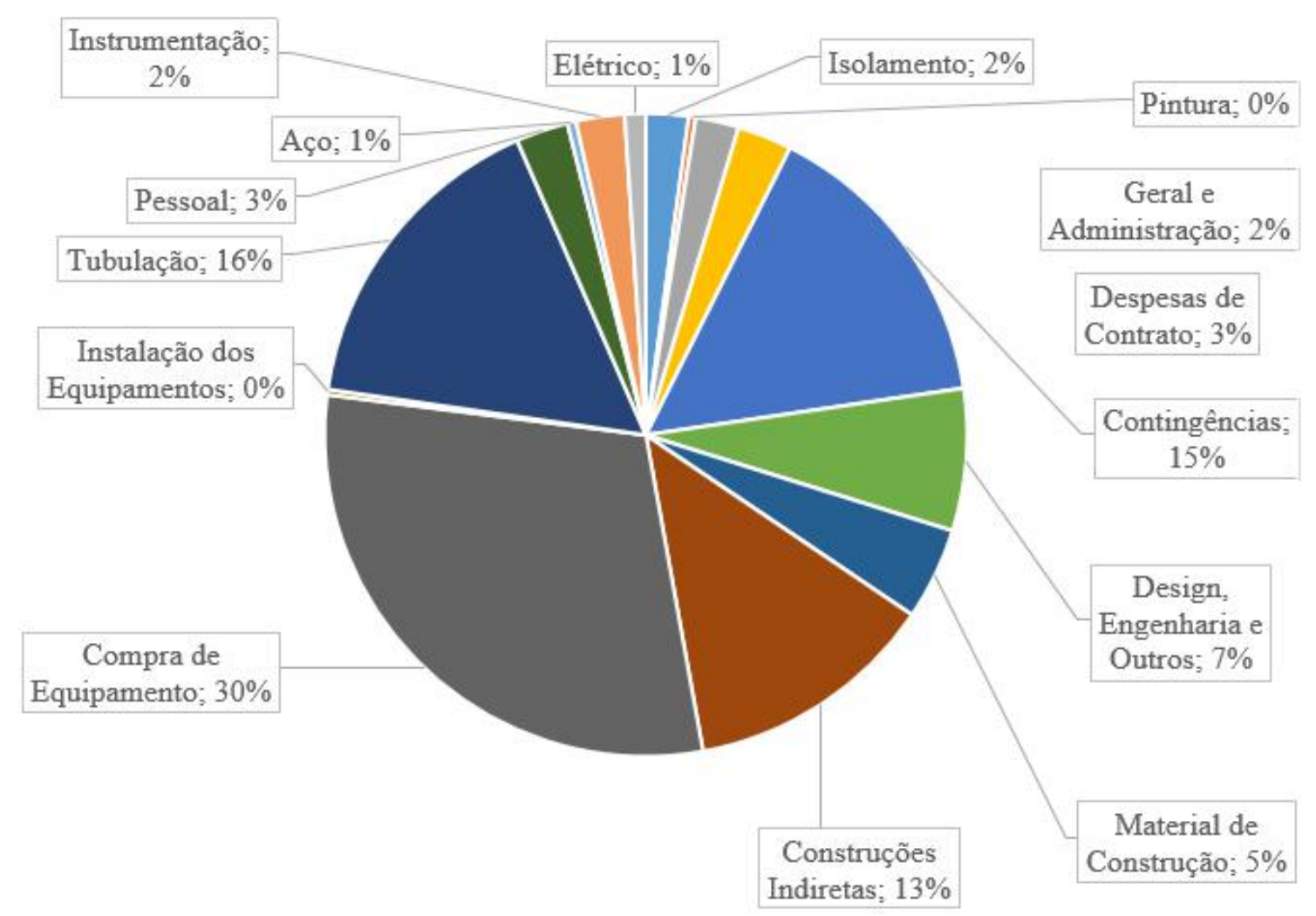

Figura 13 - Distribuição do Custo Capital do Projeto com Hidrotérmico.

\subsection{Análise Econômica}

Através dos resultados encontrados e considerando que a produção agrícola do sorgo sacarino tem rendimento de 85 toneladas de sorgo por hectare (BARCELOS, 2012), foi possível a elaboração da Tabela 11, que compara os resultados dos três pré-tratamentos, indicando a produtividade bem como o Minimum Sale Price (MSP) calculado para cada situação. 
Tabela 11 - Comparação dos resultados para os diferentes métodos para pré-tratamento do bagaço.

\begin{tabular}{cccc}
\hline Parâmetro & $\begin{array}{c}\text { Ácido } \\
\text { Diluído }\end{array}$ & $\begin{array}{c}\text { Explosão a } \\
\text { Vapor }\end{array}$ & Hidrotérmico \\
\hline Solubilização da Hemicelulose (\%) & 92 & 75 & 82 \\
\hline Quantidade de Etanol Produzida (ton/ano) & 408 mil & 372 mil & 420 mil \\
\hline Custo Operacional Anual (Milhões US\$) & 489,8 & 489,6 & 488,7 \\
\hline Custo Capital Total (US\$) & 83,3 & 93,8 & 91,9 \\
\hline Produtividade Industrial (L/ton sorgo) & 115 & 105 & 119 \\
\hline Rendimento total (L/ha) & 9775 & 8925 & 10115 \\
\hline MSP (US\$/kg) & $\mathbf{1 , 2 4}$ & $\mathbf{1 , 3 7}$ & $\mathbf{1 , 2 0}$ \\
\hline
\end{tabular}

Ao analisar o custo da produção conjunta do etanol de primeira e segunda geração a partir do sorgo sacarino, observa-se um valor superior ao preço de venda mercado. Como observado, o MSP do processo foi de US\$ 1,20 US\$ 1,24 e US\$ 1,37, por quilograma de etanol, utilizando os pré-tratamentos Hidrotérmico, Ácido diluído e Explosão a Vapor respectivamente.

Os resultados indicam que o pré-tratamento hidrotérmico é o melhor pré-tratamento para a produção conjunta de primeira e segunda geração. Isto porque este método apresenta a maior produção de etanol por tonelada de sorgo sacarino, de $10115 \mathrm{~L} / \mathrm{ha}$, e além disso o seu MSP é o menor entre os três pré-tratamentos, o que indica menores custos para produção utilizando este método.

Comparando o valor de MSP encontrado para este processo com o MSP do etanol produzido por outros materiais lignocelulósicos observa-se que eles são correlatos. Stephen, Mabee e Saddler (2012) calcularam um MSP de 1,11 US\$/kg para produção a partir das folhas do milho e de acordo com o BNDES (2010) o custo para produção a partir do bagaço da cana de açúcar é de 0,842 US\$/kg.

Para efeito de comparação, os rendimentos em quantidade de etanol por tonelada de biomassa e quantidade de etanol por hectare, para diferentes culturas, inclusive do sorgo, podem ser encontrados na Tabela 12. 
Tabela 12 - Rendimentos em L/ton biomassa e L/ha para diferentes culturas.

\begin{tabular}{ccc}
\hline Cultura & Rendimento (L/ton) & Rendimento (L/ha) \\
\hline Cana-de-Açúcar - $1^{\mathrm{a}}$ Geração & 81,9 & 7371 \\
\hline $\begin{array}{c}\text { Cana-de-Açúcar - Produção conjunta de } 1^{\mathrm{a}} \text { e } 2^{\mathrm{a}} \\
\text { Geração (Pré-tratamento Hidrotérmico) }\end{array}$ & 109 & 9810 \\
\hline Sorgo Sacarino - ${ }^{\mathrm{a}}$ Geração & 85 & 7225 \\
\hline $\begin{array}{c}\text { Sorgo Sacarino - Produção conjunta de } 1^{\mathrm{a}} \text { e } 2^{\mathrm{a}} \\
\text { Geração (Pré-tratamento Hidrotérmico) }\end{array}$ & 119 & 10115 \\
\hline Milho (grão) & 388 & $3.460-4020$ \\
\hline Milho (Palha) & - & $1050-1400$ \\
\hline Mandioca & - & 3310 \\
\hline Trigo & 376 & 2590 \\
\hline Beterraba Sacarina & $94-102$ & $5010-6680$ \\
\hline Swichgrass & 280 & 10760 \\
\hline
\end{tabular}

Fonte: Albarelli 2013, Barcelos 2012

A produção integrada de etanol de primeira e segunda geração a partir do sorgo utilizando o pré-tratamento hidrotérmico apresentou maior rendimento e aparentou ser a alternativa mais promissora.

A competitividade dos processos de segunda geração depende da redução de custos. Em países como os Estados Unidos da América os produtores recebem subsídios do governo para produzir etanol de origem celulósica, fazendo o preço abaixar e tornando o produto mais competitivo (BNDES, 2010).

A fim de diminuir o valor do MSP, uma alternativa seria a realização da integração energética dessa planta, como foi feito no trabalho da Albarelli (2013) para a produção de etanol de segunda geração a partir da cana de açúcar.

Outra forma seria utilizar o excedente de bagaço e também da lignina residual da etapa de pré-tratamento para produzir energia térmica para utilizar no próprio sistema ou para cogeração de energia elétrica. Utilizando o bagaço não só para a produção de etanol como no presente trabalho, mas também para produção e venda de energia, encontrando um valor ótimo de utilização do mesmo para os dois fins. Além disso, pode-se realizar a pesquisa com outros tipos de sorgo e outras culturas.

Outra alternativa seria a fabricação de um coproduto, como por exemplo o furfural, produzido a partir da xilose proveniente da hemicelulose dissolvida na etapa de prétratamento. Todas essas alternativas tem o objetivo de tornar a planta de produção de etanol a partir do sorgo sacarino economicamente viável. 


\subsection{Variação Paramétrica}

A fim de analisar os efeitos causados pela quantidade de sorgo sacarino processada, foi realizada uma variação paramétrica envolvendo essa variável. Duas situações foram avaliadas. No Caso 1 processaram-se 350 ton/h de sorgo, diminuição de $30 \%$ do valor inicial, e no Caso 2, processaram-se 650 ton/h de sorgo, aumento de $30 \%$ do valor inicialmente processado. Os novos MSP foram calculados e os resultados estão apresentados na Tabela 13.

Tabela 13 - MSP para Variação Paramétrica.

\begin{tabular}{cccc}
\hline Parâmetro & Ácido Diluído & Explosão a Vapor & Hidrotérmico \\
\hline $\begin{array}{c}\text { MSP (Caso 1) } \\
(\mathrm{US} \$ / \mathrm{Kg})\end{array}$ & 1,269 & 1,400 & 1,253 \\
\hline $\begin{array}{c}\text { MSP (Caso 2) } \\
(\mathrm{US} \$ / \mathrm{Kg})\end{array}$ & 1,170 & 1,336 & 0,987 \\
\hline $\begin{array}{c}\text { MSP Padrão } \\
(\mathrm{US} \$ / \mathrm{Kg})\end{array}$ & 1,244 & 1,367 & 1,205 \\
\hline
\end{tabular}

Os resultados indicam que quanto maior a quantidade de sorgo sacarino processada, menor o custo de produção do etanol. Isso se dá devido ao aumento da quantidade de etanol produzida. Pode-se concluir que mesmo aumentando-se os custos relacionados ao aumento da capacidade da planta, ocorre uma diminuição do MSP devido ao aumento da quantidade de etanol produzida.

Avaliando todos os casos de variação, o pré tratamento hidrotérmico continuou sendo o processo com o menor MSP, US $\$ / \mathrm{kg}$ 0,987, para a situação em que a quantidade de sorgo processada aumenta em $30 \%$. Acredita-se que processando quantidades diárias maiores de bagaço e fazendo-se uso do pré-tratamento hidrotérmico, a produção do etanol a partir das frações sacarínea e lignocelulósica do sorgo sacarino seja economicamente viável.

A Figura 14 representa graficamente os resultados da variação paramétrica e torna evidente os melhores resultados obtidos pelo pré tratamento hidrotérmico. Observa-se que o MSP do método de explosão a vapor depende menos da variação da quantidade de sorgo utilizada, o que não acontece com o processo hidrotérmico, onde a variação da quantidade sorgo altera muito o valor do MSP. 


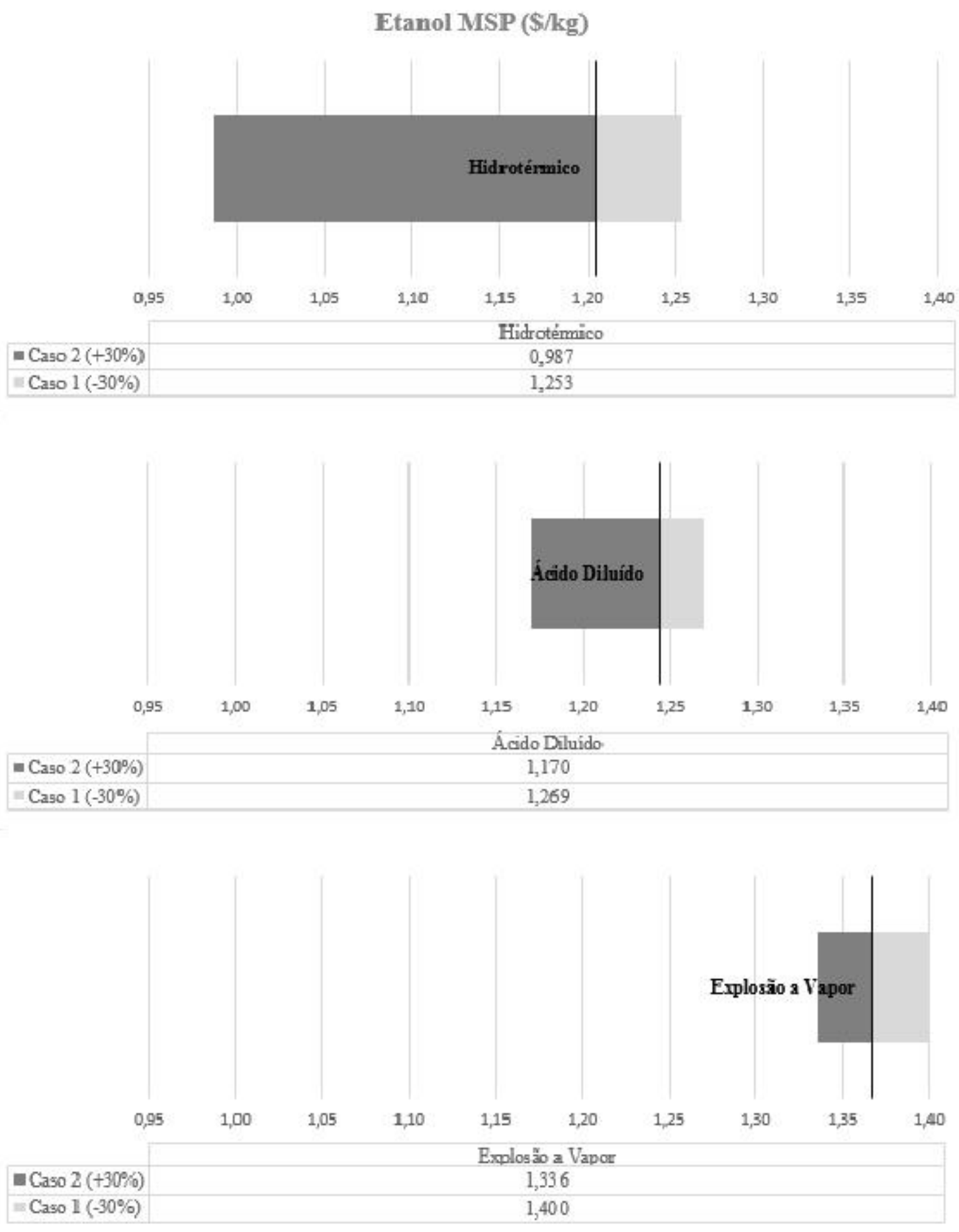

Figura 14 - Variação Paramétrica. 


\section{CONCLUSÃO}

Ao se fazer uma análise econômica dos custos de operação através das simulações realizadas, observou-se que as utilidades quentes são responsáveis pelos maiores gastos. Devido ao seu ótimo rendimento, o sorgo se mostra uma alternativa bastante promissora, principalmente para ser cultivado nos períodos de entressafra da cana e em regiões onde a cana não se adapta, promovendo, assim a ampliação do período de uso das usinas de etanol. A produção de etanol através da fração lignocelulósica é mais viável economicamente utilizando-se o pré-tratamento hidrotérmico, comparado com o ácido diluído e com o explosão a vapor. Além disso o pré-tratamento hidrotérmico apresentou maior produção de álcool, com produção de $10115 \mathrm{~L} / \mathrm{ha}$. A variação paramétrica evidenciou que o custo da produção está diretamente ligado a quantidade de etanol produzida, mesmo havendo aumento dos custos relacionados ao aumento da capacidade da mesma. Dessa forma, conclui-se que quanto maior a produção de etanol, menor o custo de produção e consequentemente maior a viabilidade da planta.

\section{REFERÊNCIAS}

ALBARELLI J. Produção de açúcar e etanol de primeira e segunda geração: simulação, integração energética e análise econômica. Tese de Doutorado - Faculdade de Engenharia Química da Universidade Estadual de Campinas, Campinas, 2013.

ALVIRA P., TOMAS-PEJO E., BALLESTEROS M., NEGRO M. J. Pretreatment technologies for an efficient bioethanol production process based on enzymatic hydrolysis: A review. Bioresource Technology, v.101, p. 4851-4861, 2010.

BARCELOS, C. A. Aproveitamento das frações sacarínea, amilácea e lignocelulósica do sorgo sacarino [Sorghum Bicolor (L.) Moench, para a produção de bioetanol]. Tese de Doutorado - Universidade Federal do Rio de Janeiro, Rio de Janeiro, 2012.

BERECHE, R. P. Modelagem e integração energética do processo de produção de etanol a partir da biomassa de cana-de-açúcar. Tese (Doutorado em Engenharia Mecânica) - Faculdade de Engenharia Mecânica da Universidade Estadual de Campinas, Campinas, SP, 2011.

BNDES, De promessa a realidade: como o etanol celulósico pode revolucionar a indústria da cana-de-açúcar -uma avaliação do potencial competitivo e sugestões de política pública. Biocombustíveis, p. 237 - 294, 2011.

CARDONA, C. A.; QUINTERO, J. A.; PAZ, I. C. Production of bioetanol for sugarcane bagasse: status and perspectives. Bioresource Technology, v.101, 2010.

DIAS, M. O. S. Desenvolvimento e otimização de processos de produção de etanol de primeira e segunda geração e eletricidade a partir da cana-de-açúcar. Tese (Doutorado) - Faculdade de Engenharia Química, Universidade Estadual de Campinas, 2011.

DIAS, M.O.S. Simulação do processo de produção de etanol a partir do açúcar e do bagaço, visando a integração do processo e a maximização da produção de energia e excedentes do bagaço. Dissertação (Mestrado) - Faculdade de Engenharia Química, 
Universidade Estadual de Campinas, Campinas, SP, 2008.

DOGARIS I., KARAPATI S., MAMMA D., KALOGERIS E., KEKOS D. Hydrothermal processing and enzymatic hydrolysis of sorghum bagasse for fermentable carbohydrates production. Bioresource Technology, v. 100, p; 6543-6549, 2009.

EMYGDIO B. M., Produção de etanol a partir de sorgo sacarino. Grupo Cultivar, 2009. Disponível

em: $<$ http://www.grupocultivar.com.br/ativemanager/uploads/arquivos/artigos/Artigo_sorgo Beatriz.pdf $>$. Acesso em 16 de nov. 2016.

ESALQ - Indicador Semanal CEPEA/ESALQ. Disponível em $<$ http://cepea.esalq.usp.br/etanol/>. Acesso em: 21 de nov. 2016.

ICIS Princing. Disponível em $<$ http://www.icis.com/chemicals/>. Acesso em: 15 de out. 2016.

JUNQUEIRA, T. L. Análise de viabilidade Ténico-Econômica de Alternativas de Processo para Produção de Etanol no Brasil. Tese (Doutorado em Engenharia Química) - Faculdade de Engenharia Química da Universidade Estadual de Campinas, Campinas, SP, 2015.

MAY, A.; et al. Sistema Embrapa de produção agroindustrial de sorgo sacarino para bioetanol: Sistema BRS1G - Tecnologia Qualidade Embrapa, Sete Lagoas: Embrapa Milho e Sorgo, 120p., 2012.

SIPOS B., RÉCZEY J., SOMORAI Z., KÁDÁR Z., DIENES D., RÉCZEY K. Sweet Sorghum as feedstock for ethanol production: enzymatic hydrolysis of steam-pretreated bagasse. Applied Biochemistry and Biotechnology, v. 153, p. 151-162, 2009.

STEPHEN, J.D.; MABEE, W.E.; SADDLER, J.N. Will second-generation ethanol be able to compete with first-generation ethanol? Opportunities for cost reduction. Biofuels, Bioproducts and Biorefining, v. 6, n.2, p. 159-176, 2012.

SUN, Y., CHENG, J., Hydrolysis of lignocellulosic materials for ethanol production: a review. Bioresource Technology v. 83, p. 1-11, 2002.

TALEBNIA, F. KARAKASHEV D., ANGELIDAKI I. Production of bioethanol from wheat straw: An overview on pretreatment, hydrolysis and fermentation. Bioresource Technology v. 101 p. 4744-4753, 2010.

WOOLEY, R. J.; PUTSCHE, V. Development of an ASPEN PLUS Physical Property Database for Biofuels Component. Washington: Office of Scientific and Technical Information, U.S. Dept. of Energy, 1996.

YU, Y.; LOU, X.; WU, H. Some Recent Advances in Hydrolysis of Biomass in HotCompressed Water and Its Comparisons with Other Hydrolysis Methods. Energy and Fuels, v.22, p.46-60, 2008. 


\title{
SIMULATION AND TECHNICAL ECONOMICS ANALYSIS OF THE PRODUCTION OF BIOETHANOL FROM THE SACARINE AND LIGNOCELLULOSIC FRACTIONS OF SWEET SORGHUM
}

\author{
G. A. L. SOUZA ${ }^{1}$, G. C. MENEZES ${ }^{1}$ e F. Á. RODRIGUES ${ }^{1}$ \\ ${ }^{1}$ Universidade Federal de Viçosa, Departamento de Química \\ E-mail: farrodrigues1@gmail.com
}

\begin{abstract}
Sugarcane is the main raw-material for ethanol production in Brazil, although it has restrictions on its production cycle. Thus, sweet sorghum, could be seen as an alternative during the sugarcane off season. The simulation for production of first and second generation ethanol from sweet sorghum, in an integrated process, was executed, using the software Aspen HYSYS. For the second generation, the bagasse of sorghum must be pre-treated. In this work, the pretreatments hydrothermal, dilute acid and steam explosion were evaluated with an integrated production and the costs were estimated by the economic analysis and the results were US\$ 1,205, US \$ 1,244 and US \$ 1,367, per kilo of ethanol, respectively. By the parametric variation, it was observed that ethanol production is economically viable for larger quantities of processed material. The lowest production value was US\$ $0.987 / \mathrm{kg}$ ethanol, using the hydrothermal pretreatment, processing 650 tons $/ \mathrm{h}$ of sorghum.
\end{abstract}

KEYWORDS: Sweet-Sorghum; First and Second Generation Bioethanol; Pretreatment; Simulation; Aspen HYSYS; Analysis Economics. 